\title{
Recycling Thermal Insulation Materials: A Case Study on More Circular Management of Expanded Polystyrene and Stonewool in Switzerland and Research Agenda
}

\author{
Valeria Superti $^{1, *}$, Tim V. Forman ${ }^{2} \mathbb{D}$ and Cynthia Houmani ${ }^{1}$ \\ 1 Laboratory on Human-Environment Relations in Urban Systems (HERUS), École Polytechnique Fédérale de \\ Lausanne (EPFL), 1015 Lausanne, Switzerland \\ 2 Cambridge Institute for Sustainability Leadership, University of Cambridge, Cambridge CB2 1QA, UK \\ * Correspondence: valeria.superti@epfl.ch
}

Citation: Superti, V.; Forman, T.V.; Houmani, C. Recycling Thermal Insulation Materials: A Case Study on More Circular Management of Expanded Polystyrene and Stonewool in Switzerland and Research Agenda. Resources 2021, 10, 104. https://doi. org/10.3390/resources10100104

Academic Editor: Ruben Vrijhoef

Received: 1 September 2021

Accepted: 8 October 2021

Published: 13 October 2021

Publisher's Note: MDPI stays neutral with regard to jurisdictional claims in published maps and institutional affiliations.

Copyright: (c) 2021 by the authors. Licensee MDPI, Basel, Switzerland. This article is an open access article distributed under the terms and conditions of the Creative Commons Attribution (CC BY) license (https:// creativecommons.org/licenses/by/ $4.0 /)$.

\begin{abstract}
The limits to linear models of production based on material extraction, manufacture, use, and disposal are becoming increasingly apparent across the global economy. The Circular Economy (CE) describes an alternative to this problematic "take-make-waste" linear model that is concerned with resource efficiency and waste minimization. The construction and demolition sector represents an important focus for a CE transition due to its significant environmental impact. The use of thermal insulation to reduce energy demand associated with heating and cooling in buildings is vital for reducing the sector's high environmental impact; however, there are significant challenges to recycling thermal insulation materials (IM). This study examines these challenges in the context of Switzerland and evaluates the potential for more circular management of expanded polystyrene and stonewool IM. The research provides an original analysis of the Swiss IM value chain in the context of the CE agenda based on a literature review, semi-structured interviews, and a workshop. Research gaps are highlighted based on scientific literature. The roles and agency of actors involved in the Swiss IM value chain are examined. Enablers of and barriers to wider IM recycling as reported by workshop participants are outlined. Interventions for tackling the current challenges faced for the recycling of thermal IM are suggested. Finally, an agenda for future research is proposed. Throughout the discussion, the importance of the involvement, commitment, and collaboration of stakeholders across the entire IM value chain for an effective and expedient transition to a $\mathrm{CE}$ is highlighted.
\end{abstract}

Keywords: circular economy; insulation material; recycling; barriers; workshop; research agenda

\section{Introduction}

The global production and consumption of goods, coupled with population growth and economic development, is increasingly unsustainable. The Circular Economy (CE) offers an alternative economic model that is regenerative and sustainable in comparison to the prevailing yet problematic "take-make-waste" linear model [1]. The CE model entails fundamental changes in how materials are sourced, used, and disposed of, which are necessary to make our economies more sustainable.

The construction and demolition (C\&D) sector has a significant impact on the environment [2], and therefore is a key target for CE interventions [3]. Key actions to make the C\&D sector more circular include: (i) recycling; (ii) minimizing resource depletion [4-6]; (iii) avoiding the use of toxic materials [7]; and (iv) diverting waste from landfilling [8]. Despite the diversity of actions needed to transition to a CE, research has shown that recycling has to date been the most implemented circular strategy [9].

Insulation materials (IMs) are critical to the decarbonization of the C\&D sector and to improving thermal comfort and reducing household expenditure on fuel $[10,11]$. The sustainable management of IMs, however, faces significant challenges [12]. One example is 
expanded polystyrene (EPS), which until recently in Europe was manufactured with brominated flame retardants such as hexabromocyclododecane (HBCD), which are considered toxic and persistent organic pollutants [13,14]. Safe recycling of EPS installed before 2015 requires the elimination of $\mathrm{HBCD}$ and other hazardous chemicals [15], which introduces technical complexity and added costs to the process.

At present, the predominant material pathways for most IMs are landfilling and waste-to-energy treatment [16]. These pathways are the least conducive to a CE [17], and are intrinsically unsustainable and insufficient to manage future increases in waste volumes [18]. Strategies for sustainable thermal IM waste management that align with planetary limits are urgently needed. Recycling offers the most effective strategy for mitigating IM waste and reducing its environmental impact, and should therefore be increased [16,19]. This is echoed by [20], who identified increasing use of recycled material in stonewool and extruded polystyrene (XPS) production processes as the most realistic and effective way to increase circularity in the C\&D sector. However, multiple barriers to recycling IMs still exist. Although previous research has proposed strategies for enhancing recycling [20], further research is needed to provide empirical evidence to show how recycling processes can be implemented across the value chain (i.e., considering the supply and reverse chain of IMs and their recirculation flows).

This paper reports research that addresses this gap in the literature. The research was conducted in the context of Switzerland. The Swiss IM market is composed principally of six materials, which account for $95 \%$ of the nation's insulation market: EPS, XPS, polyurethane (PUR), glass wool, stonewool, and wood fiberboard. EPS and stonewool represent the highest volumes of installed material in their respective categories (oil- and mineral-based [18]), and so comprise the focus of the research reported here.

In 2015, the amount of IMs installed in Switzerland was approximately 234,000 tons, of which EPS accounted for approximately 26,100 tons and stonewool for approximately 87,500 tons [16]. EPS is one of the most widely produced basic polymers in the world [21]. It is used in numerous applications, from thermal insulation in buildings to packaging (including food packaging), landscaping, and road construction. In Switzerland, the recycling of EPS from building construction occurs through its collection into dedicated bags that are sent to an EPS manufacturing company. The manufacturer subsequently incorporates a percentage of the recycled EPS into the production of new IM [16]. Stonewool is composed of volcanic rock, typically basalt and dolomite. It is used for thermal insulation in buildings and is generally deposited in landfills at the end of its useful life [22]. In Switzerland, stonewool recycling is managed similarly to the EPS recycling scheme: the manufacturer receives clean cuttings and deconstructed parts, and after processing them, mixes them with production waste and reprocesses them into stonewool insulation [16]. Despite their wide use, these materials are recycled at a marginal rate in Switzerland, with only $1.5 \%$ of approximately 59,700 tons of deconstructed material currently recycled [16].

Based on their prevalence in the C\&D sector market in Switzerland and internationally-and considering the relative market-readiness of relevant waste management technology_EPS and stonewool were selected as the focus of this research, which examined the barriers to, and enablers of, IM recycling. These materials have already been the subject of substantive research and case studies in previous works. For instance, ref. [20] focused on the benchmarking and comparison of IMs' carbon footprint and circularity. However, it is acknowledged that assessing the drivers of, and barriers to, transitioning to a circular future for IM should be based on a systems perspective [20], considering the entire value chain [13]. Few scientific studies explicitly focused on the structure of the IM value chain and on the role and potential agency of the involved actors for driving a systemic CE transition. More investigation is needed to identify, evaluate, and strategically address the barriers to embedding CE principles in the IM value chain. Developing related insights will support the identification of leverage points and targets for $\mathrm{CE}$ interventions.

This research documented experts' perspectives among IM value chain stakeholders to examine the drivers of, and barriers to, circular management of EPS and stonewool thermal 
insulation. The research provides an original analysis of the IM value chain in the context of the widely observed exigency of transitioning to more circular resource management. In this study, we: (i) highlight research gaps based on scientific literature; (ii) examine the roles and agency of actors involved in the Swiss IM value chain; (iii) outline enablers of, and barriers to, wider IM recycling as reported by workshop participants; (iv) suggest interventions for tackling the current challenges faced for the recycling of thermal IM; and (v) propose an agenda for future research.

\section{Materials and Methods}

This study was performed in three steps: (i) a literature review of the pertinent scientific publications; (ii) semi-structured interviews with subject-matter experts; and (iii) a workshop with professionals in the IM value chain and recognized CE experts.

\subsection{Literature Review}

The goals of the literature review were to understand (i) which research streams on EPS and stonewool have been explored in recent research; and (ii) the relevant gaps in the research literature concerning the circular management of EPS and stonewool.

The literature review of scientific papers related to EPS and stonewool was performed in December 2020 and was developed following established literature review procedures [23], by searching the Scopus database using combinations of keywords. For stonewool, we used the string ("stonewool" OR "stone wool" OR "rock wool" OR "rockwool") AND ("insulati" ${ }^{* \prime)}$ in the title, abstract, and keywords, starting from 2010, and limiting the sample to the English language and journal articles reporting primary research and review papers. We screened 197 documents. For EPS, we used the string ("EPS" OR "expanded polystyrene") AND ("insulati*") in the title, abstract, and keywords, and applied the same filters. We screened 423 documents. To include all relevant sources of information related to sustainability and CE for IMs, we searched for related items using the search string ("insulation material" OR "EPS" OR "expanded polystyrene" OR "stonewool" OR "stone wool" OR "rock wool" OR "rockwool") AND ("circular" OR "sustainable" OR "sustainability") in the title, starting from 2010. We obtained 19 additional items.

To analyze the literature, we applied an inductive categorization framework. This approach can be found in analogous research (e.g., $[24,25])$. We screened the title and abstract of the papers and assigned a code for each topic covered. Each paper could be associated with multiple topics. The creation of topics was revised after the first screening of the papers. The assignment of the codes was performed twice by two researchers independently and discussed between them to reach an agreement. The individual topics were grouped into six broad categories, which are shown in Table 1.

Table 1. Topics and subcategories of topics used for the literature review.

\begin{tabular}{|c|c|}
\hline Topic & Sub-Topic \\
\hline 1. Performance and technical properties assessment & $\begin{array}{c}\text { 1.1 Properties and Performance: Insulation } \\
\text { 1.2 Properties: Fire } \\
\text { 1.3 Properties: Acoustic } \\
\text { 1.4 Properties: Moisture } \\
\text { 1.5 Properties: Structural/Mechanical } \\
\text { 1.6 Properties: Deterioration }\end{array}$ \\
\hline $\begin{array}{l}\text { 2. Environmental performance, impact, management, and } \\
\text { assessment }\end{array}$ & $\begin{array}{c}\text { 2.1 Lifecycle impact assessment/LCA studies } \\
\text { 2.2 Human impact on reserves/MFA } \\
\text { 2.3 Sustainability (explicit mention) } \\
\text { 2.4 Circular Economy (explicit mention) } \\
\text { 2.5 Recycling process, technology, applications, materials, other } \\
\text { 2.6 Waste management } \\
\text { 2.7 Health }\end{array}$ \\
\hline
\end{tabular}


Table 1. Cont

\begin{tabular}{cc}
\hline Topic & Sub-Topic \\
\hline 3. Social impact, management, and assessment & 3.1 Safety \\
& 3.2 Social issues \\
\hline 4. Economic factors and assessment, logistics & 4.1 Efficiency subsidies \\
& 4.2 Supply chain and logistics \\
& 4.3 Insurance premiums \\
5. Other & 4.4 Financials and economic analysis and aspects \\
\hline 6. Out of scope & 5.2 Marginal \\
\hline
\end{tabular}

Additionally, based on the information available in the literature [16,26], a first map (scheme) representing the supply and reverse chain of IMs in Switzerland, along with the potential actors involved at each stage or process, was generated, as reported in Section 3.

\subsection{Expert Interviews}

The semi-structured interviews aimed to: (i) complement and interrogate the conclusions of the literature review; (ii) revise the IM value chain map based on the interviewees' critical feedback; (iii) better understand the role and potential agency of actors involved in the value chain of IMs in Switzerland as well as the interrelations between them; and (iv) inform the design of the subsequent research stage (i.e., the workshop).

Twelve semi-structured interviews were conducted in English, Italian, or French using the video conference software Zoom or a telephone. In Appendix A Table A1, we report additional information about the interviewed experts. The experts were selected based on: (i) their tenure in relevant organization; (ii) the researchers' evaluation of their subject matter expertise; and (iii) the experts' availability to conduct an interview in one of the selected languages. Each interview lasted approximately one hour. All interviews were recorded, transcribed, anonymized, and translated into English if necessary. Content analysis of the transcripts was based on a semi-structured and iterative coding procedure using MAXQDA software. The goals of analyzing the interview transcripts were to collect information about the role of actors, the interaction among actors at specific steps of the material flows, the enabling and hindering factors of IM recycling, potential interventions for enhancing IM recycling, and ideas for a research agenda. The codes and sub-codes of each category were created using an iterative approach by analyzing each transcript and discussing it between the researchers [27,28], reiterating the coding process until a consensus was reached. The insights from the interviews were used to refine the IM value chain map that was initially developed using information from the literature $[16,26]$.

\subsection{Workshop}

The term workshop is interpreted as "an arrangement whereby a group of people learns, acquire new knowledge, perform creative problem-solving, or innovate in relation to a domainspecific issue" [29]. Workshops as research methodology are specifically designed to fulfill a research purpose: to produce reliable and valid data about the domain in question [29]. In this research, a workshop was organized with the aims to: (i) document participants' perspectives on the results obtained through the literature review and interviews; (ii) assess perceived effectiveness and feasibility of the interventions that the research team suggested to enhance IM recycling; and (iii) identify and examine the self-reported agency of participants in relation to those interventions.

Thirteen experts participated in a two-hour online workshop organized using the video conferencing software Zoom, a collaborative whiteboard app (Padlet), and a collaborative spreadsheet application (Google Spreadsheet). In Appendix A Table A2, we 
report additional information about the participants. Four of the workshop attendees already participated in the interviews of the earlier research stage. Before the event, the participants were asked to answer an online questionnaire to rank the barriers hindering IM recycling according to the perceived urgency of lifting those barriers. During the workshop, the preliminary results of the literature review and the interviews were presented to the participants, and two discussion sessions were held in parallel groups of six and seven participants. In the first session, the participants reflected on the ranking of the barriers as a result of the pre-workshop survey to reach a consensus on the relative importance of each barrier. In the second session, three to four experts per group graded the potential interventions proposed for enhancing IM recycling, based on: (i) their perceived effectiveness (i.e., in terms of enhancing the IM recycling rate if implemented); and (ii) based on their perceived feasibility (i.e., in terms of potential for implementation), in Switzerland, in the upcoming 5 to 10 years. Each group focused on scoring two interventions. All the interventions and their scores were combined in a matrix (see Section 4). Following the scoring exercise, the experts were prompted to discuss ways in which they could intervene (as individuals or as part of their organization) to enable the implementation of interventions.

\section{Results}

\subsection{Literature Review}

The subtopics identified in the literature review and the respective frequency of their appearance in search results are shown in Table 2 (the heat map shows which subtopics were covered the most). For stonewool, 128 documents were classified as out of scope or marginal; for EPS, there were 68. These were not included in the table. In Appendix A, we report additional information on the sources of the screened articles (Tables A3 and A4), and the evolution of the number of published studies since 2010 (Figures A1 and A2).

Three main streams of research were identified through the literature review: broad literature on the performance and technical properties of the selected IM; specific studies on Life Cycle Assessment; and analyses on the financial aspects (mostly economic savings) of IM installation and use. We elaborate on these three main streams of research in the paragraphs below and identify pertinent research gaps.

The topic "Performance and technical properties assessment" appeared as the most frequently investigated topic for both materials. This result reflected the importance of energy and hygrothermal performance of IMs during the operational life of buildings. The literature identified in this group focuses on structural and mechanical properties of the selected IM, safety and fire resistance prerequisites, and hygrothermal performance.

The subtopic "Lifecycle impact assessment/LCA studies" was relevant for approximately a quarter of the studies on stonewool and EPS. As the C\&D sector faces increasing economic and environmental sustainability challenges within the context of a competitive and globalized economy, environmental criteria and assessments have become increasingly important in the design and construction decision-making process [20]. Lifecycle environmental assessments quantify the whole life or embodied environmental impact of IM and associated construction by accounting for resource and energy flows from cradle to gate, site, grave, or cradle [30].

The sub-topic "Financials and economic analysis and aspects" was covered by approximately one-third and one-sixth of the literature in our sample on stonewool and EPS, respectively. This subtopic included studies focused mainly on lifecycle total cost analyses, often conducted alongside lifecycle environmental assessments, to determine optimum IM layer type and thickness, and consequent lifecycle energy savings, payback periods, and capital cost of IM installation.

When examining which categories remained underrepresented, the category incorporating the recycling process and technology of EPS and stonewool, and the applications of these recycled IM, was covered by only a small fraction (approximately one-tenth) of the screened papers. These papers tackled the use of recycled EPS or stonewool waste, alongside other materials, for applications of recycled materials and the generation of new 
products (e.g., new concrete material [31]; nanofibers with uses for filtration [32]; sustainable alkali-activated materials for structural applications [33]; alkali-activated cementitious binders [34]; and alkali-activated stonewool [35]).

Table 2. Coverage of subtopics identified in the literature review ("out of scope" and "marginal" topics excluded). The color scheme (from white to black) reflect the low (white) or high (black) relative coverage of each subtopic.

\begin{tabular}{|c|c|c|c|}
\hline Topic & Subtopic & EPS & Stonewool \\
\hline \multirow{6}{*}{$\begin{array}{l}\text { Performance and technical properties } \\
\text { assessment }\end{array}$} & Properties and Performance: Insulation & & \\
\hline & Properties: Fire & & \\
\hline & Properties: Acoustic & & \\
\hline & Properties: Moisture & & \\
\hline & Properties: Structural/Mechanical & & \\
\hline & Properties: Deterioration & & \\
\hline \multirow{7}{*}{$\begin{array}{l}\text { Environmental performance, impact, } \\
\text { management and assessment }\end{array}$} & Lifecycle impact assessment/LCA studies & & \\
\hline & Human impact on reserves/MFA & & \\
\hline & Sustainability (explicit mention) & & \\
\hline & Circular Economy (explicit mention) & & \\
\hline & $\begin{array}{c}\text { Recycling process, technology, applications, } \\
\text { materials, and other }\end{array}$ & & \\
\hline & Waste management & & \\
\hline & Health & & \\
\hline \multirow{2}{*}{$\begin{array}{l}\text { Social impact, management and } \\
\text { assessment }\end{array}$} & Safety & & \\
\hline & Social issues & & \\
\hline \multirow{4}{*}{$\begin{array}{l}\text { Economic factors and assessment, } \\
\text { logistics }\end{array}$} & Efficiency subsidies & & \\
\hline & Supply chain and logistics & & \\
\hline & Insurance premiums & & \\
\hline & Financials and economic analysis and aspects & & \\
\hline
\end{tabular}

While several research studies explored the IM recycling processes and applications, the "Waste management", "Supply chain and logistics", "Social issues", and "Circular Economy" topics received the least attention in the papers screened. For the waste management of IM, the emphasis was essentially on: (i) the assessment of special treatment options for the removal of flame retardants associated with waste polymers ([36]); (ii) on External Thermal Insulation Composite Systems' waste management chains, routes, and economically and ecologically beneficial waste treatment options; and (iii) benchmarking the carbon footprint and circularity of the production processes of EPS and stonewool by using carbon and circularity indicators [20].

The literature review revealed no information on the structure of the value chain of EPS and stonewool and their circular management, nor on the role or agency of system actors who have the potential to drive a transition to the C\&D sector's circularity and sustainability. Expanding the research to different IMs, we found some relevant previous research. Notably, Ref. [16] described the Material Flow Analysis of IMs in Switzerland in aggregate terms, which by inference provided some insight into the flow of stonewool and EPS.

The results of the literature review suggested that broad interest in circular and sustainable management of EPS and stonewool exists, but showed that substantive assessment of pathways to sustainable management is to date largely underdeveloped. Hence, the literature review reinforced our focus on two main research areas: (i) the structure of stonewool and EPS value chains and the agency of actors within the IM socio-technical systems; and (ii) the potential enablers of and barriers to widespread IM recycling.

\subsection{IM Value Chain Map and Actors' Roles and Agency}

Based on the work performed in [26] and [16], and the insights derived from the expert interviews, we developed a list of actors involved in the IM value chain (Table 3), and the Swiss IM value chain map (Figure 1). In Table 3, actors who are mostly involved in 
each step of the value chain are identified, and brief descriptions of their professional roles are provided. In Figure 1, a qualitative material flow analysis is paired to the identification of which actors play a role in deciding how a specific step would take place. For example, at the IM production stage, four main actors were identified: producers of IMs, certification organizations, researchers, and authorities. All these actors have agency in steering how the production process works, the composition of the material, and the requirements for its production. Similarly, the map pictures the entire value chain and offers a global overview of the types of collaborations that could be established among specific actors at different stages of the value chain. The scheme provided by Ref. [26], which drew a system diagram of the supply and reverse chain for EPS packaging in Brazil, represented a starting point to prepare and iterate the Swiss IM value chain. However, since Ref. [26] focused on EPS for packaging, some steps (especially in the production and distribution phases) needed to be adjusted. Ref. [16] developed a material flow analysis of IMs in Switzerland. In comparison to this scheme, Figure 1 provides a focus on the production and end-of-life of products containing IMs, and the potential management of IMs abroad. Furthermore, in addition to both schemes by Refs. [16,26], Figure 1 assigns the involved actors at each step of the IM value chain.

Table 3. Actors involved in the IM value chain (supply and reverse chain) and their potential role and agency.

\begin{tabular}{c} 
Actor \\
\hline Thermal insulation material producers
\end{tabular}

Role/Agency

Producers of (recycled) thermal IMs in Switzerland and abroad. IMs can either be entirely produced from virgin raw materials, or both virgin raw materials and recycled materials. IM waste to be recycled can either be directly imported from abroad or generated within Switzerland, during the production stage itself (i.e., at the producer's site), during the installation phase at the construction site, or during the recycling phase that follows building renovation/deconstruction or that occurs at the end of life of IM products (e.g., EPS, stonewool, etc.). IM waste can be either issued from the C\&D sector or other sectors. IMs produced in Switzerland can either be exported outside Switzerland, or used within Switzerland as input to make other products or to be distributed and installed in buildings.

Producers of goods and materials other than thermal IMs for the C\&D sector.

Other producers These goods and products can incorporate (recycled) IMs (e.g., sandwich panels, concrete).

Distributors

Installers

Authorities and policymakers
Actors in charge of distributing IMs from producer sites located within Switzerland or abroad, to the building's construction and installation sites.

\begin{tabular}{cc}
\hline Installers & Actors in charge of the installation of IMs in buildings and at the construction sites. \\
\hline & Actors such as legislative bodies, Swiss federal and cantonal offices, departments \\
within cantonal authorities (such as the Department of Environment and Safety, \\
municipalities, etc.) that have a role in setting laws, legislation, directives, legal \\
requirements and procedures (regulations and standards), taxation, etc., that are \\
related to the handling, treatment, and disposal of (C\&D) waste (e.g., sorting, \\
collection, recycling, thermal valorization, landfilling of waste, etc.), to the \\
handling of environmental, ecological, health and safety matters, building \\
and policymakers \\
$\begin{array}{c}\text { C\&-related matters (installation and demolition techniques, practices, products } \\
\text { used in buildings), and production processes and material-related matters. }\end{array}$ \\
\hline
\end{tabular}

The building or construction project owner initiates the construction project. In most cases, they are the client. The project owner is responsible for the funding of the construction project, and for contracting the services of the third parties

Project owner implicated in the design and construction. The construction project owner, or the contracting authority, can either be a person, a private legal entity (a firm or an association), or a public institution (i.e., public authority).

Architects and engineers

Architects and engineers provide subject-matter expertise, and manage and work jointly during the planning, design, and construction stages of a building or construction project. 
Table 3. Cont.

\begin{tabular}{ccc}
\hline Actor & Role/Agency \\
\hline Researchers & $\begin{array}{c}\text { Researchers have a role in conducting research; and in investigating, developing, } \\
\text { and fostering innovation in processes, technologies, products and materials, } \\
\text { techniques, and practices. Their research scope can cover the production phase, } \\
\text { the installation and renovation/deconstruction phases, and the recycling phase. }\end{array}$ \\
Certification organizations & $\begin{array}{c}\text { Organizations or certifying bodies that are accredited for a sector and that can } \\
\text { deliver and grant compliance certificates. They are acknowledged by the } \\
\text { authorities of the involved sector. They are responsible for assessing whether the } \\
\text { system, product, process, or organization meets and fulfills the certifications and } \\
\text { standards requirements. }\end{array}$
\end{tabular}

Actors responsible for influencing, advising, and consulting project owners, architects and engineers, and construction companies on the planning, design

Independent consultants/advisors (techniques, practices, and materials), execution, and delivery stages of the construction project. They have a role in promoting ecological labels and standards, sustainable and environmental design, and installation and construction practices and techniques.

Homeowners

Recycling companies

Recycling associations

Construction companies

Construction associations
The homeowner has a choice in selecting an IM for their home, whether it is for a new installation or renovation.

Companies responsible for the material valorization and the recycling process of waste IM received.

Associations that represent, endorse, and protect the interests of the waste recycling industry, vis-à-vis the authorities, legislative and specialized bodies, and the general public. Cooperating with other industry bodies and companies, they develop market-oriented recycling solutions and action plans. They raise awareness and promote the implementation of best practices and principles for the collection, sorting, and recycling treatment of (C\&D) waste. They have a role in elaborating relevant (quality) standards and procedures, influencing and advising legislative bodies, project owners, C\&D companies, and recycling companies in matters related to materials use, valorization, and recycling.

Construction or contracting companies are responsible for the planning, leading, execution, management and administration, and supervision of building construction, from the start of the project until its end.

Construction associations manage training and information platforms and sharing, focusing their activities on the publication of instruments for the construction of ecological and sustainable buildings. These instruments help to optimize the planning, construction, management, and deconstruction of buildings.

Construction associations can group several members, spanning federal (public) and private construction offices and departments, government entities and authorities, associations for architects and engineers, public project owners, etc.

Actors responsible for the transport of collected and sorted waste material, from installation and renovation/deconstruction sites to the final waste treatment facilities (recycling facilities, thermal valorization facilities, or landfill facilities).

Deconstruction companies

Companies responsible for the deconstruction, dismantling, and demolition process of buildings.

Sorting companies

Companies responsible for receiving (mixed) waste material, sorting, and separating it into individual waste components or fractions.

Thermal valorization facilities

Facilities responsible for the thermal valorization of waste material after it is inspected to meet standards and quality requirements.

Facilities designed to receive waste that is not thermally or materially valorized

Landfilling facilities 
Insulation material (IM) supply and reverse chain

(1) Lampos, 2019

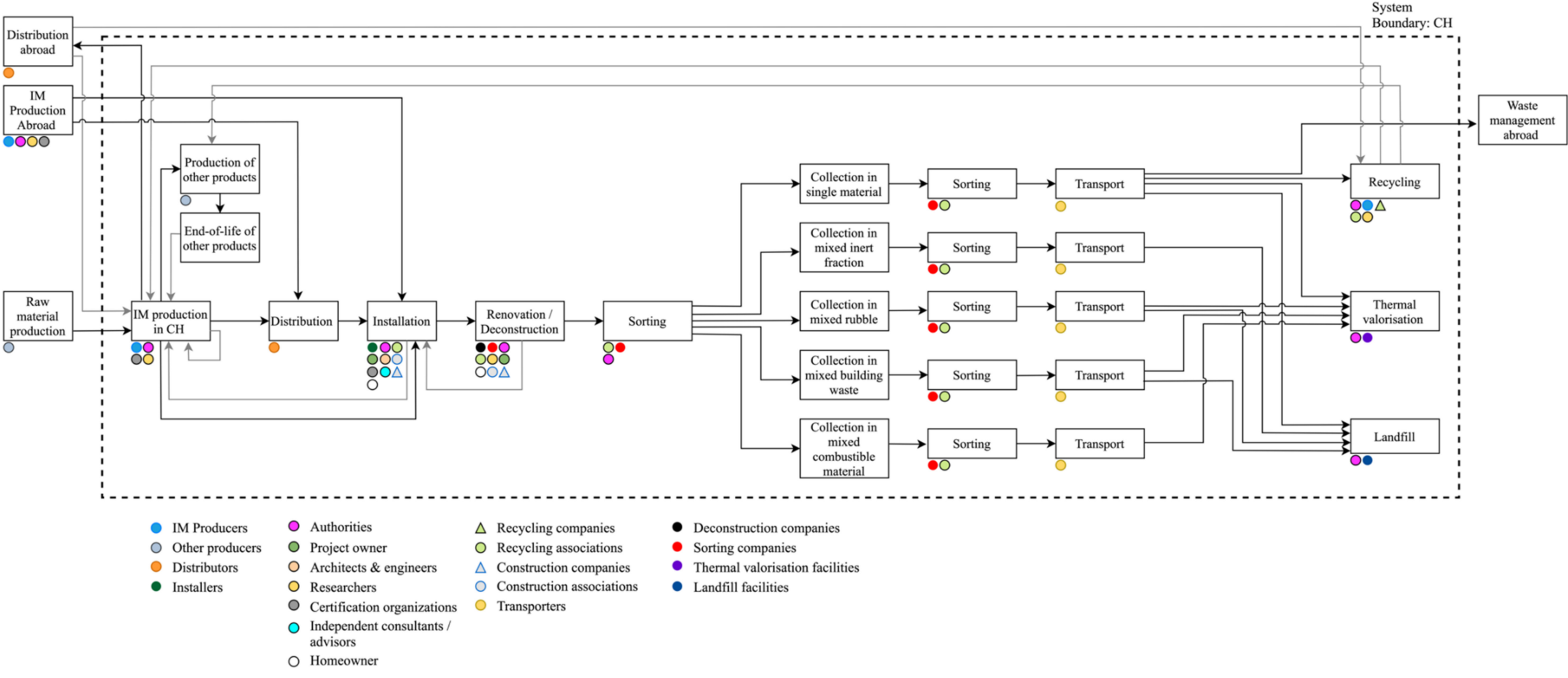

Figure 1. The IM value chain in Switzerland and involved actors at each step. 


\subsection{Enablers of and Barriers to IM Recycling}

Potential factors enabling the recycling of IMs identified through the literature review and content analysis of the transcripts of the interviews are reported in Table 4 . The enablers relate to: (i) the level of actors' concern about environmental issues and their ecological culture; (ii) marketing benefits associated with the use of recycled materials or the engagement into the recycling process; (iii) legal requirement to recycle IMs; (iv) product requirements if a specific environmental quality label is pursued; and (v) economic incentives to recycle and economic sustainability of the recycling process.

Table 4. The enablers of IM recycling.

\begin{tabular}{ccc}
\hline Enabler & Description \\
\hline Environmental concern and ecological culture & $\begin{array}{c}\text { Environmental/sustainability awareness of the actors and } \\
\text { commitment to more eco-friendly and sustainable products, } \\
\text { processes, design, etc. }\end{array}$ \\
\hline Marketing benefits & $\begin{array}{c}\text { Benefits deriving from the interest for sustainability and CE } \\
\text { application in the C\&D sector, positive image, and positive public } \\
\text { interest for companies promoting a circular management of IMs. }\end{array}$ \\
\hline Legal requirements & $\begin{array}{c}\text { Control, directives, (eco)norms, regulatory obligations, standards, etc. } \\
\text { dictating the use of recycled IMs, the recycling of IM waste over } \\
\text { alternative waste treatment options, ensuring public and private } \\
\text { entities' adherence and alignment, and/or influencing prices and } \\
\text { taxes associated with raw and secondary materials use and waste } \\
\text { treatment options. }\end{array}$ \\
\hline Label requirements & $\begin{array}{c}\text { Building label certifications oriented towards sustainability and the } \\
\text { CE; e.g., requiring sustainable building practices, or use of } \\
\text { sustainable and recycled IM. }\end{array}$ \\
\hline Economic incentives and viability & $\begin{array}{c}\text { Higher cost of alternative end-of-life solutions, higher price of virgin } \\
\text { raw materials, lower price of recycled materials, reduced recycling } \\
\text { costs, and favorable economic balance of recycling. }\end{array}$
\end{tabular}

Table 5 reports the barriers to recycling IMs, as elicited through the literature review and the expert interviews. These barriers are ranked and listed in order of their importance, as evaluated by the workshop participants. Barriers related to costs and logistics were considered the most important; i.e., the ones that should be lifted first. This was followed by: (i) quality and technical requirements; (ii) awareness and commitment; (iii) legislation, legal requirements, and control; and finally, (iv) lack of an established network, cooperation, and ambiguous responsibility of different actors. In relation to the costs, we noted that the cost of virgin materials may be higher or lower than the cost of recycled materials across different IM regional markets over time. Hence, the price of virgin raw materials was cited as an enabling factor (if the price of virgin raw materials was higher than for recycled ones) and a barrier (in the opposite case). 
Table 5. Barriers to IM recycling. The column "Sources" specifies if the information was derived from a specific document or through the expert interviews.

\begin{tabular}{|c|c|c|}
\hline Barriers & Examples & Sources \\
\hline \multirow{6}{*}{ Costs and logistics } & Lower cost of virgin raw materials & {$[8,37,38]$} \\
\hline & $\begin{array}{l}\text { Low economic value of the waste materials and lack of market for secondary } \\
\text { raw materials }\end{array}$ & [39] \\
\hline & $\begin{array}{l}\text { Elevated cost of storage and handling of IM waste, given IM low density and } \\
\text { cost of required associated machines and infrastructures }\end{array}$ & [37] \\
\hline & $\begin{array}{c}\text { Elevated cost of transport, given IM low density and under-optimal logistics } \\
\text { and transport network }\end{array}$ & {$[8,38]$} \\
\hline & $\begin{array}{c}\text { Low cost of disposal methods alternative to recycling (i.e., low landfilling and } \\
\text { thermal valorization cost) }\end{array}$ & {$[8,37,38]$} \\
\hline & $\begin{array}{l}\text { Unequal costs and benefits sharing among the different } \\
\text { IM-involved stakeholders }\end{array}$ & [20] \\
\hline \multirow{5}{*}{$\begin{array}{l}\text { Quality and technical } \\
\text { requirements }\end{array}$} & Insufficient IM waste quality and purity for recycling & {$[20,37,40,41]$} \\
\hline & $\begin{array}{l}\text { Health concerns over the quality of the recycled product, as IM waste may } \\
\text { contain harmful compounds (e.g., HBCD) }\end{array}$ & [16] \\
\hline & $\begin{array}{l}\text { Difficult separation of IM waste from C\&D waste due to nonselective } \\
\text { demolition and infrequent buildings disassembly practices }\end{array}$ & {$[16,20,41,42]$} \\
\hline & $\begin{array}{l}\text { Lack of adequate technology to analyze the IM waste material for adequate } \\
\text { recycling process choices and performance assessment }\end{array}$ & [41] \\
\hline & Energy balance of the recycling process & Interviews \\
\hline \multirow{3}{*}{$\begin{array}{l}\text { Awareness and } \\
\text { commitment }\end{array}$} & Reluctance to recycle stemming from negative "waste" image & Interviews \\
\hline & $\begin{array}{l}\text { Favored use of products made entirely from virgin raw materials as opposed } \\
\text { to products containing recycled content, due to habits, routine use, and culture }\end{array}$ & Interviews \\
\hline & $\begin{array}{c}\text { Insufficient knowledge, best practices, and idea sharing and awareness about } \\
\text { the recycling of IMs and the use of recycled IMs }\end{array}$ & Interviews \\
\hline \multirow{2}{*}{$\begin{array}{l}\text { Legislation, legal } \\
\text { requirements, and control }\end{array}$} & Legal impediments (e.g., legislation dictating IMs as waste) & [37] \\
\hline & Inconsistent/insufficient follow-up control by the authorities & Interviews \\
\hline \multirow{4}{*}{$\begin{array}{l}\text { Network, cooperation, and } \\
\text { responsibility }\end{array}$} & Insufficient collaboration and exchange among actors & [43] \\
\hline & Lack of industrial network & Interviews \\
\hline & $\begin{array}{l}\text { Lack of responsibility and obligation after production, diluted sense of } \\
\text { responsibility among actors }\end{array}$ & Interviews \\
\hline & Lack of willingness to recycle other producers' products & Interviews \\
\hline
\end{tabular}

\subsection{Interventions for Improving IM Recycling Rate}

As reported in Tables 4 and 5, the interviews provided rich insights into perceived barriers to, and enablers of, IM waste recycling. These point to potential interventions or leverage points in the IM recycling system that could enable and accelerate the transition to a circular IM management. Analysis of interview transcripts identified new insights into potential interventions and actions to drive increased material recovery and recycling. These interventions are shown in Table 6 and are described primarily in response to the critical barriers mentioned in Section 3.3. 
Table 6. Potential interventions and actions addressing barriers and aimed at enhancing IM recycling.

\begin{tabular}{c}
\hline Interventions \\
\hline EPR and scheme harmonization
\end{tabular}

Collaboration with a material cadaster platform (e.g., Madaster:

https: / / www.madaster.ch accessed on 12 October 2021)

\section{Description}

Enforcement of Extended Producer Responsibility and harmonization of the recycling scheme (to avoid "one-producer recycling scheme" set in place)

\section{Barrier Addressed}

Network, cooperation, and responsibility
Collaboration of the IM value chain actors (e.g., producers, recyclers, deconstruction companies) with the Madaster (building Material Cadaster) platform, which enables product traceability and the tracking of buildings materials and components, and facilitates the use, reuse, recycling, and recovery of materials
Enhancement of recycling processes and technologies (e.g., collaboration with the PolyStyreneLoop recycling project, aimed at developing at industrial scale an innovative purification process based on the CreaSolv ${ }^{\circledR}$ Technology, allowing the recycling of thermal IM waste containing additives and flame retardants)
Support of awareness campaigns, advertisements, networking events (e.g., involvement of communication experts to enhance the "image" of waste), and support, implementation, and spread of best practices within Switzerland and benchmark with foreign best practices (e.g., building IM installation techniques and practices, materials choice, waste handling, recycling scheme, etc.)
- Network, cooperation, and responsibility
- Network, cooperation, and responsibility

- Quality and technical requirements
- $\quad$ Awareness and commitment

- Quality and technical requirements
Label requirements

Follow-up controls
Expansion of label requirements to promote recyclability
- Legislation, legal requirements, and control
Increase of follow-up controls at demolition sites
- $\quad$ Legislation, legal requirements, and control
Price increase of end-of-life alternatives

Increase of prices (taxes) of alternative waste (end-of-life) treatment options
- Costs and logistics

- $\quad$ Legislation, legal requirements, and control
Enhancement of the necessary logistics network (e.g., between waste collection

Logistics network sites, recycling facilities, producers, establishment of collection points, fostering of partnerships enabling the optimal functioning of the network)

The scoring exercise of the suggested interventions performed by the workshop participants resulted in a matrix in which interventions were mapped according to their feasibility and effectiveness in enabling IM recycling (Figure 2). According to the matrix, the interventions could be grouped into four categories. Three interventions (increasing awareness and sharing best practices, the improvement of the recycling technology-for 
example, via the one proposed by the PolyStyreneLoop project (https: / / polystyreneloop.eu (accessed on 12 October 2021) for recycling thermal IM containing flame retardants-and the improvement of the logistic network) were rated as the most feasible and effective, and should thus be prioritized. Furthermore, two interventions (the collaboration of the IM value chain actors with a building material cadaster platform-e.g., Madaster-and the enforcement of an Extended Producer Responsibility (EPR) scheme) were rated as very effective and feasible, and could then represent the second focus of action. The intervention implying the expansion of label requirements to promote IM recyclability was scored as the most feasible intervention, while having moderate effectiveness. This could highlight the rather limited impact of label requirements, despite the easiness of implementation. Finally, two interventions (the price increase of end-of-life alternatives-such as landfilling and incineration-and increasing formal follow-up controls to check that IM waste is correctly handled) were scored as quite effective but only moderately feasible, showing how their implementation would need a more complex restructuring of the value chain and coordination and agreement among several stakeholders.

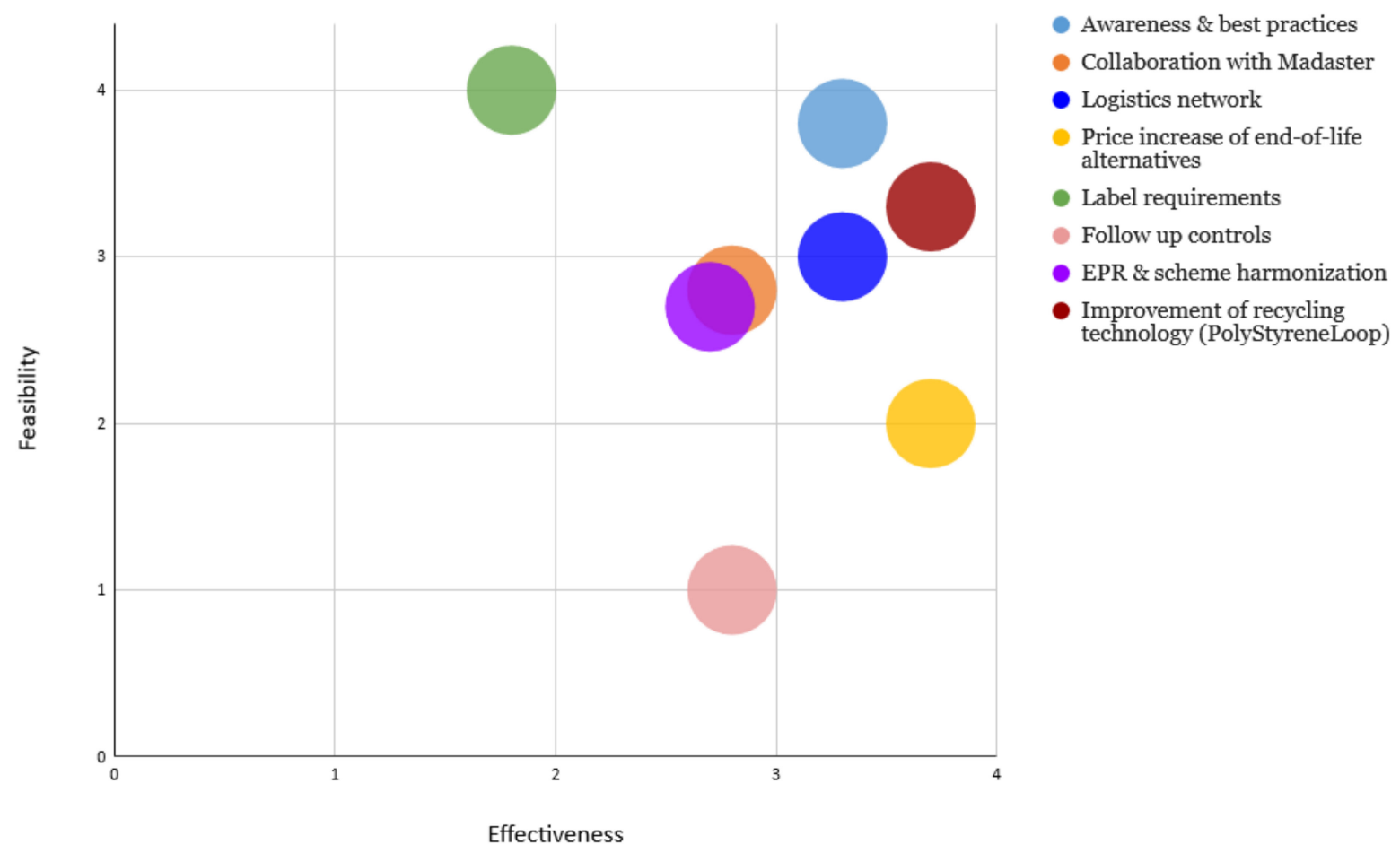

Figure 2. Intervention scoring matrix, based on feasibility and effectiveness (score: 0: not effective/not feasible; 1 : slightly effective/feasible; 2 : moderately effective/feasible; 3 : very effective/feasible; 4 : extremely effective/feasible).

\section{Discussion}

This study was undertaken to better understand enablers of and barriers to circular resource management in the IM value chain. We: (i) reviewed current scientific literature and highlighted relevant research gaps; (ii) considered roles and potential agency of actors involved in the value chain of IMs; (iii) elicited enablers and barriers for the recycling of IMs; and (iv) suggested potential interventions and actions. In the discussion section, we will elaborate specifically on each of these points and, finally, will propose a research agenda for tackling the current challenges to the recycling of thermal IM.

\subsection{IM Value Chain, and Enablers of and Barriers to IM Recycling}

The results of this research allowed us to draw a scheme of the IM value chain. This map condenses information related to material flows and social networks in a qualitative form, eliciting which actors play an important role at each step of the IM value chain. 
The importance of this visualization lies in summarizing all the steps through which IMs go, from production to end of life. This visualization offers the opportunity for interest parties to implement actions or establish collaborations that could affect how each step is performed, in order to improve IM recyclability. As collaboration is key to overcoming barriers related to the implementation of $\mathrm{CE}$ principles, and since many collaboration solutions can be put in place [44], knowing which actors might have agency within the same value chain step offers a valid tool to support partnerships. For example, this could support public actors-identified as key agents for change toward more sustainable actions [45] - in selecting parties to contact in order to establish strategic partnerships.

This research contributed to the production of knowledge to elicit drivers and barriers of IM recycling to implement CE principles specifically in the C\&D sector. A point that merits attention is the manner in which barriers and enablers should be prioritized for effective use of resources and maximum impact on the transition towards a circular IM management. In the literature, this has been done, for example, by expert judgment of the importance of removing a specific barrier [46]. In the workshop organized for our study, the ranking of barriers by the participants questioned how some aspects of the IM recycling obstacles could be interconnected. For example, the lack of an established network of actors for establishing industrial symbiosis goes hand in hand with the low value of recycled materials, which do not have a market yet.

\subsection{Interventions for IM Recycling}

In order to overcome the barriers identified and leverage the pertinent enablers, the prioritization of the interventions provided by the research team was conducted through the scoring exercise performed by the workshop participants, in which interventions were scored according to the perceived feasibility and the effectiveness of the intervention. When initiating change and devising an action plan, it is crucial to prioritize and begin by first focusing on the interventions that are the most effective in addressing the issues raised, and that are the most feasible for implementation and achievement of the anticipated outcomes $[47,48]$. While the most effective intervention might not always be the most feasible, often a balance of effectiveness and feasibility should be targeted. As shown in the results section, the scoring of the interventions according to the above-mentioned parameters resulted in the identification of four main groups of interventions: those with great feasibility and effectiveness in enabling IM recycling; those that are rather feasible and effective; two interventions that might be quite effective but are not very feasible; and finally one intervention that would be very feasible, but quite ineffective.

In the first group, the interventions were related to: (i) increasing awareness and sharing best practices; (ii) improving the recycling technology (for example, via the one proposed by the PolyStyreneLoop project for recycling thermal IM containing flame retardants); and (iii) improving the logistics network. First, the usefulness of disseminating guidelines and educating future architects or other key C\&D stakeholders regarding the effective implementation of best practices (e.g., design, materials selection, and use) was emphasized throughout the workshop, and was recognized in the pertinent scientific literature on CE in the C\&D sector [49-51]. Guidelines were recognized to be very effective in building confidence among the different stakeholders. Raising awareness and evaluating potential practices and actions that could be done to promote the recyclability of IM (and a CE in the C\&D sector in general) is essential for actors to recognize, change, or adopt new methods and ways of doing $[52,53]$. Second, the improvement of the recycling process and technology, as could be considered by the PolyStyreneLoop project [13,54], earned a highly effective and feasible score. As stated by the invited experts, there is too little material recycled and recovered compared to the total volume of waste produced, and technological improvements could offer disruptive solutions. There is a major challenge to maintaining product quality and purity associated with the introduction of recycled IMs in the production process. Hence, it is important to have the appropriate recycling technology to mitigate this concern. By tackling this issue, the barriers faced in regard 
to secondary materials market availability and demand could also be resolved, as more satisfactory recycled materials would be available for actors to use, even outside of the C\&D sector, which would support the establishment of industrial symbiosis $[55,56]$. Third, in terms of enhancing the logistics network, interventions targeting logistics improvements were considered very feasible and effective. However, as discussed throughout the workshop, this network improvement could depend on the particular area considered and the prevalent constraints. For the specific case of Switzerland, the country is also relatively small, so further development of the logistics network could be achieved within its regions. According to the experts, there is a potential to further optimize the storage, transport, and scheduling across the network, and the control of costs (storage, handling, and transport) would allow for the extension and the higher efficiency of the logistics network. These interventions relate to improvements of reverse logistics that appear in scientific literature examining construction waste topics [57-60].

In the second group, interventions were linked to: (i) the collaboration of the IM value chain actors with a building material cadaster platform-e.g., Madaster-and (ii) the enforcement of an Extended Producer Responsibility scheme. First, the collaboration with Madaster, a relatively recent platform that has gained momentum in the C\&D sector in Europe [61], was assessed as very feasible and would allow collecting material data throughout the building's entire lifetime. This would be important for resource and product tracking, recovery, and reuse, thus rendering this intervention very effective, which is linked to the benefits of material passports in general $[62,63]$. Second, as for the enforcement of the Extended Producer Responsibility, the importance of identifying the final entity/agent responsible for IM waste recycling was raised throughout the discussion. Specifically, the expert working for an IM producer acknowledged their responsibility and stressed the growing consideration and importance their company (the producer) gives to recycling processes that would allow the reintroduction of almost all produced materials into the value chain. However, the harmonization of the recycling scheme was judged as rather tricky by the workshop participants, who outlined the significant role that the legislation could have in this regard in establishing an EPR scheme for IM, adopting a top-down approach [64].

The third group of interventions was related to the expansion of label requirements to promote IM recyclability. The workshop experts emphasized the need to promote and expand the adoption of standards and labels that require environmentally friendly IMs, such as those with recycled content. It was argued that these standards and labels should be leveraged and supported by the whole network of C\&D actors, which resonates with recent literature highlighting the positive effect of targeting environmental labels [65]. However, as long as labels encourage but do not sufficiently consider or urge the use of recycled materials, or are not widely adopted by actors, the effect of this intervention in increasing the IM recycling rate would be moderate. As for the case of an EPR scheme, top-down interventions were deemed to represent a valid solution.

Finally, the last group of interventions was related to the price increase of end-oflife alternatives_-such as landfilling and incineration-and increasing formal follow-up controls to check that IM waste is correctly handled. First, the price or tax increase of alternative end-of-life and waste treatment solutions, which was considered extremely effective but moderately feasible, would indeed incentivize actors to recycle [18]. The workshop participants highlighted how higher disposal costs for landfilling or thermal valorization would represent the first motivation for individuals to recycle, while environmental concerns might come in second place. However, the needed political will and the legal changes required to implement this intervention seemed difficult to attain and the process might likely be (politically) slow. Second, the increase of follow-up controls at demolition sites stood out as the least feasible, as this intervention would require significant commitment and efforts, especially from the authorities' side, although its importance is acknowledged in the literature [66]. Nonetheless, the implementation of this intervention 
would be very effective in ensuring the separation of demolition waste and an increased recovery and recycling rate of IMs.

In summary, the interventions discussed comprised potential ideas that involve both bottom-up and top-down approaches to adapt CE guidelines to the specific case of IM waste recycling. Knowledge is still needed to advance our understanding of how CE can be effectively implemented in the $C \& D$ sector. Hence, suggestions for future research are presented in the following section, specifically focused on a research agenda for improving the recycling of IMs.

\subsection{Research Agenda}

Building on the gaps identified in the literature and the insights collected through the interviews and the workshop, future lines of research deemed important to enhance and improve the circular management of IMs are summarized in a proposed research agenda (Table 7), which is aimed at tackling the identified barriers. Specifically, further research could focus on: (i) the improvement of IM recycling technology; (ii) the optimization of the recycling scheme; (iii) the assessment of risks inherent to the use of current or alternative IMs; (iv) the possibility to use alternative components that could avoid the use of pollutants/problematic materials; (v) the development of alternative building construction and installation practices; (vi) the inquiry into opportunities for recycled IMs to be used in different value chains; and (vii) alternative IMs that could replace the ones currently used and deemed less sustainable.

Table 7. Suggested research agenda and link to the barriers addressed.

\begin{tabular}{|c|c|c|}
\hline Research Agenda & Description & Barriers Addressed \\
\hline Recycling process and technology & $\begin{array}{l}\text { Development of suitable separation } \\
\text { technologies for IM waste recovery; } \\
\text { recycling process for polluted/glued IMs } \\
\text { or IMs containing flame retardants }\end{array}$ & - $\quad$ Quality and technical requirements \\
\hline Recycling scheme optimization & $\begin{array}{l}\text { Optimization and harmonization of the } \\
\text { IM recycling scheme (i.e., supply and } \\
\text { reverse chain), enabling more optimal } \\
\text { and efficient collection, sorting, logistics, } \\
\text { and transport network; more practical, } \\
\text { convenient, and cost-effective recycling } \\
\text { chain and take-back schemes }\end{array}$ & $\begin{array}{l}\text { - } \quad \text { Costs and logistics } \\
\text { Network, cooperation, and } \\
\text { responsibility }\end{array}$ \\
\hline
\end{tabular}

Study of current and alternative components used in IMs and assessment of their overall health and environmental

Future impact of available IM impact, throughout their use and components

following their end of life (i.e.,

- Quality and technical requirements assessment of their suitability for recycling and meeting performance and quality requirements)

Alternative components and avoidances of pollutants in IM

Alternative building construction and installation, and deconstruction practices building design and installation practices (modular assembly, prefabrication), and sustainable deconstruction practices, enabling optimal resource use and circularity of construction materials
Avoidance of pollutants/glues, impurities; research on potential other components to replace harmful ones
- Quality and technical requirements

- Quality and technical requirements

- Quality and technical requirements

- Costs and logistics

- Network, cooperation, and responsibility 
Table 7. Cont.

\begin{tabular}{cccc}
\hline Research Agenda & Description & Barriers Addressed \\
\hline Recycling process and technology & $\begin{array}{c}\text { Development of suitable separation } \\
\text { technologies for IM waste recovery; } \\
\text { recycling process for polluted/glued IMs } \\
\text { or IMs containing flame retardants }\end{array}$ & $\bullet$ & Quality and technical requirements \\
Alternative IMs & $\begin{array}{c}\text { Study of thermal IM that are more } \\
\text { sustainable; biodegradable; renewable; } \\
\text { ecofriendly; safer; and easier to separate, } \\
\text { collect, transport, and recycle as } \\
\text { alternatives to EPS and or stonewool }\end{array}$ & $\bullet$ & $\begin{array}{l}\text { Quality and technical requirements } \\
\text { Costs and logistics }\end{array}$ \\
\hline
\end{tabular}

\subsection{Contributions and Limitations}

The identification of the barriers and enablers for a $C E$ in the C\&D sector has received considerable attention in the recent scientific literature $[46,52,67,68]$. The contribution of the present study lies in focusing on a type of construction material (i.e., IMs), about which specialized literature on the CE is scarce. The logical integration of the results of this research entailed the understanding of which barriers impede the recycling of IMs, and then, in turn, the enablers that can be leveraged to suggest targeted interventions. By highlighting and discussing them, this research contributed to the proposal of CE interventions targeting specific barriers and leveraging recycling drivers. A visual tool (a value chain map) was developed, to understand how different actors could play a major role at specific stages of the material flows of IMs. This tool could be used by both individual actors and policymakers. The former could use it to understand their position along the value chain and establish partnerships with actors involved in the same value chain steps. The latter could use the map as a management tool to coordinate policies and understand the interlinkages among different actors at different stages of the value chain. Throughout the discussion of our results, we highlighted the importance of the involvement, commitment, and collaboration of stakeholders across the entire IM value chain for an effective and expedient transition to a CE. The emphasis on collaboration and the importance of a holistic vision relate to the concept of innovation ecosystems [69], which are key for achieving a CE [70]. Our research also contributed to promoting the discussion about CE principles in the C\&D sector by presenting the research results to trigger reflections and bringing together several actors in a workshop. Although it was not a specific aim of its inception, the workshop served to strengthen the connection among actors, thereby potentially facilitating future collaboration, which was confirmed through a follow-up survey that the workshop participants filled after the event. Particularly, the workshop fostered communication and discussion, as well as the exchange of ideas and practices among the different reunited stakeholders (e.g., government actors, academic professors and researchers, independent consultants, entrepreneurs, IM producers, recycling companies, and association representatives). In this way, the workshop indirectly created an inclusive exchange space and allowed for the establishment of a network among the several actors, strengthening the links among them. The workshop dialogues raised awareness and provided many participants with new sources of information, by considering both empirical and theoretical research findings. Additionally, the workshop activities pushed the participants to consider potential IM recycling interventions and actions, considering their feasibility and effectiveness, and they were triggered to reconsider their role in the implementation of the proposed interventions. Potential joint efforts and collaborations to foster the execution of the interventions were also raised.

There are some limitations to be considered regarding the presented research, with consequent potential implications for validity and generalizability.

First, through the literature review, we screened documents that were published from 2010. This choice was made to analyze recent literature and highlight the most recent research gaps. Expanding the analysis to literature published before 2010 could provide 
additional insights on topics related to EPS and stonewool IMs, although if not present in the review results, they could be deemed addressed. Furthermore, the completion of the literature review entailed a screening process and code allocation in which a degree of subjective judgment existed. Although the review was performed by two researchers independently, and disagreements were discussed to resolve incoherence, it is acknowledged that the analysis of the literature contained some inherent subjectivity, and hence, potential oversight and omissions.

Second, the focus of our research study on EPS and stonewool may have omitted some important issues relevant to other IMs. We note that interviewed experts were not necessarily involved only with stonewool's and EPS' value chains, and were sometimes asked to provide their inputs about IM and C\&D waste more generally. Therefore, some findings may be particularly relevant to the IMs studied, while others may bear relevance to IMs more generally. While many results may be generalizable to other material value chains, we remind the reader that our analysis was based on only two materials-including their unique technical, socio-technical, political, legal, and economic contexts-and suggest caution in drawing inferences from our findings to other materials. Future research could examine a wider set of IMs or other construction materials. However, for some materials, similar analysis as the one presented in this research could be challenging due to the current state, for example, of the recycling technology and infrastructure. As reported by [16], for example, neither XPS nor PUR IMs are currently recycled in Switzerland.

Third, we recognize that our work examined the context of a specific country, namely Switzerland. The interviews' responses, the described IM value chain, and the proposed IM value chain scheme reflect the idiosyncrasies (but also the transnational commonalities) of Switzerland. As pointed out in [51], the high variety of actors involved in the C\&D value chain creates a complex network of responsibilities, with very different decision-making chains in the different European countries. We highlight that it would be valuable to conduct studies in other countries to evaluate the feasibility and relevance of interventions outlined in this research.

Finally, potential sample and recruitment bias associated with the experts that were interviewed and that participated in the workshop existed. We recognize that more and/or nuanced perspectives and insights could have been gathered if additional stakeholders were interviewed and/or invited to the workshop. However, we obtained information saturation in the interviews, and deemed the number of participants to the workshop reasonable within time and resource constraints.

\section{Conclusions}

As increasing volumes of IM are produced and installed, marginal rates of recycling (and correspondingly high rates of waste incineration and landfilling) pose an urgent need for interventions to close material loops. This research contributes to the scientific literature on the operationalization of the CE principles in the C\&D sector and on IM circular management in particular.

We built on previous knowledge of material flows to define and map the Swiss IM value chain, including its principal stages and stakeholders, and delineated these stakeholders' roles and potential agencies. This mapping showed the relevant positions of different stakeholders within the current IM value chain, and pointed to the potential for collaborations among actors who (could) interact at the same stage of the value chain for recycling (and circularity) to be increased. The scheme could be practically used both by individual actors and by policymakers to identify collaboration opportunities and to coordinate policies aimed at increasing material circularity, fostering the establishment and development of innovation ecosystems.

Semi-structured interviews with IM value chain stakeholders helped to iterate the mapping of the IM value chain, and offered new insights on the enablers and barriers of IM recycling within Switzerland. By better understanding current enablers and barriers, targeted interventions could be identified to increase the rate of IM recycling. Those inter- 
ventions were discussed with workshop participants and assessed in terms of feasibility and effectiveness. According to this assessment, three interventions resulted being the most feasible and effective: (i) increasing awareness and sharing best practices; (ii) improving the recycling; and (iii) improving the logistics network. Moreover, by discussing the findings through the expert workshop, we outlined a new research agenda to address the barriers to-and unleveraged drivers of-widespread recycling and a circular IM value chain. Identified topics for further research include worked aimed at: (i) improving the IM recycling technology; (ii) optimizing the recycling scheme; (iii) assessing the risks inherent to the use of current or alternative IMs; (iv) evaluating the possibility to use alternative components to replace pollutants/problematic materials; (v) developing alternative building construction and installation practices; (vi) inquiring opportunities for recycled IMs to be used in different value chains; and (vi) discovering/producing alternative IMs to replace those currently used and deemed less sustainable.

In conclusion, the presented research contributed to the production of knowledge to implement the CE principles, specifically in the C\&D sector. We highlighted the importance of the involvement, commitment, and collaboration of stakeholders across the entire IM value chain for an effective and expedient transition to a CE.

Author Contributions: Conceptualization, methodology, formal analysis, investigation, writingoriginal draft, writing — review and editing, visualization, V.S.; methodology, writing—original draft, writing — review and editing, T.V.F.; methodology, formal analysis, investigation, writing-original draft, writing - review and editing, visualization, C.H. All authors have read and agreed to the published version of the manuscript.

Funding: This research was partly funded by the Swiss Federal Office for the Environment (grant no. 591517).

Institutional Review Board Statement: This study was approved by the ethics committee of EPFL HREC No: 036-2020.

Informed Consent Statement: Informed consent was obtained from all subjects involved in the study.

Acknowledgments: We would like to thank the experts that agreed to participate to the interviews and the workshop. We are specifically grateful to ecobau. We also thank Claudia R. Binder for her support and supervision. Finally, we thank three anonymous reviewers for their comments and suggestions to improve the quality of the manuscript.

Conflicts of Interest: The authors declare no conflict of interest.

\section{Appendix A}

Table A1. List of the experts interviewed. The experts were all male. The table also reports the language in which the interview was performed, and whether the expert also participated in the workshop.

\begin{tabular}{cccc}
\hline Interview ID & Affiliation & Language of Interview & Participation in the Workshop \\
\hline 1 & Recycling association & English & Yes \\
2 & Public administration & French & Yes \\
3 & IM producer & English & No \\
4 & Thermal valorization plant & French & No \\
5 & IM producer & French & Yes \\
6 & Independent consultant & French & No \\
7 & IM producer & French & No \\
8 & IM producer & English & No \\
9 & User of IMs for other products & French & No \\
10 & Public administration & Italian & No \\
12 & Building association & French & Yes \\
\hline
\end{tabular}


Table A2. List of the participants in the workshop, and their gender and affiliation.

\begin{tabular}{|c|c|c|c|}
\hline Participant ID & Affiliation & Gender & Participation in the Interviews \\
\hline 1 & Recycling association & Male & Yes \\
\hline 2 & Independent consultant & Male & Yes \\
\hline 3 & IM producer & Male & No \\
\hline 4 & Entrepreneur/material bank & Female & No \\
\hline 5 & Researcher center on logistics & Male & No \\
\hline 6 & Recycling association & Male & Yes \\
\hline 7 & Recycling center & Male & No \\
\hline 8 & IM producer & Female & No \\
\hline 9 & Recycling center & Male & No \\
\hline 10 & Construction company & Male & No \\
\hline 11 & IM producer & Male & No \\
\hline 12 & Public administration & Male & Yes \\
\hline 13 & Research center in construction & Male & No \\
\hline
\end{tabular}

Table A3. Sources of articles screened in the literature review on stonewool and the percentage they represented out of the total sample $(n=98)$. Sources linked to only one article are grouped under "Others".

\begin{tabular}{|c|c|}
\hline Source (Name of Journal) & $\%$ \\
\hline Energy and Buildings & 8.4 \\
\hline Construction and Building Materials & 4.5 \\
\hline Fire and Materials & 3.9 \\
\hline Fire Technology & 3.2 \\
\hline Applied Thermal Engineering & 1.9 \\
\hline Building and Environment & 1.9 \\
\hline Energy & 1.9 \\
\hline Energy Sources, Part A: Recovery, Utilization and Environmental Effects & 1.9 \\
\hline Journal of Cleaner Production & 1.9 \\
\hline Materials & 1.9 \\
\hline Advances in Materials Science and Engineering & 1.3 \\
\hline Applied Acoustics & 1.3 \\
\hline ASHRAE Journal & 1.3 \\
\hline Buildings & 1.3 \\
\hline Canadian Acoustics-Acoustique Canadienne & 1.3 \\
\hline Case Studies in Thermal Engineering & 1.3 \\
\hline Energies & 1.3 \\
\hline Energy Education Science and Technology Part A: Energy Science and Research & 1.3 \\
\hline Energy Efficiency & 1.3 \\
\hline Environmental Progress and Sustainable Energy & 1.3 \\
\hline Fire Safety Journal & 1.3 \\
\hline International Journal of Automotive and Mechanical Engineering & 1.3 \\
\hline Journal of Hazardous Materials & 1.3 \\
\hline Magazine of Civil Engineering & 1.3 \\
\hline Materials and Design & 1.3 \\
\hline Renewable and Sustainable Energy Reviews & 1.3 \\
\hline Thermal Science and Engineering Progress & 1.3 \\
\hline Thin-Walled Structures & 1.3 \\
\hline Others & 45.2 \\
\hline
\end{tabular}




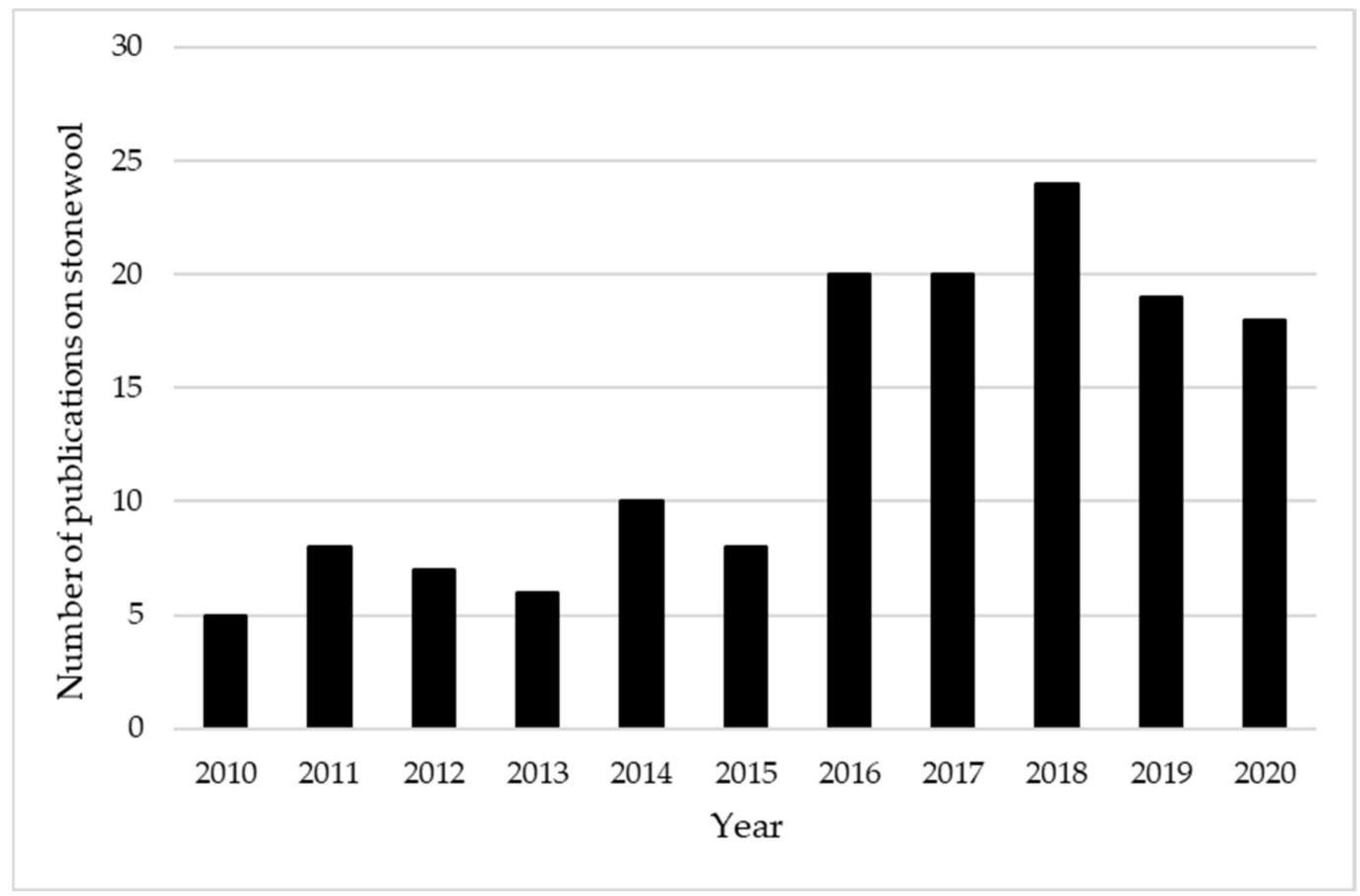

Figure A1. Number of publications on stonewool per year, as analyzed in the literature review.

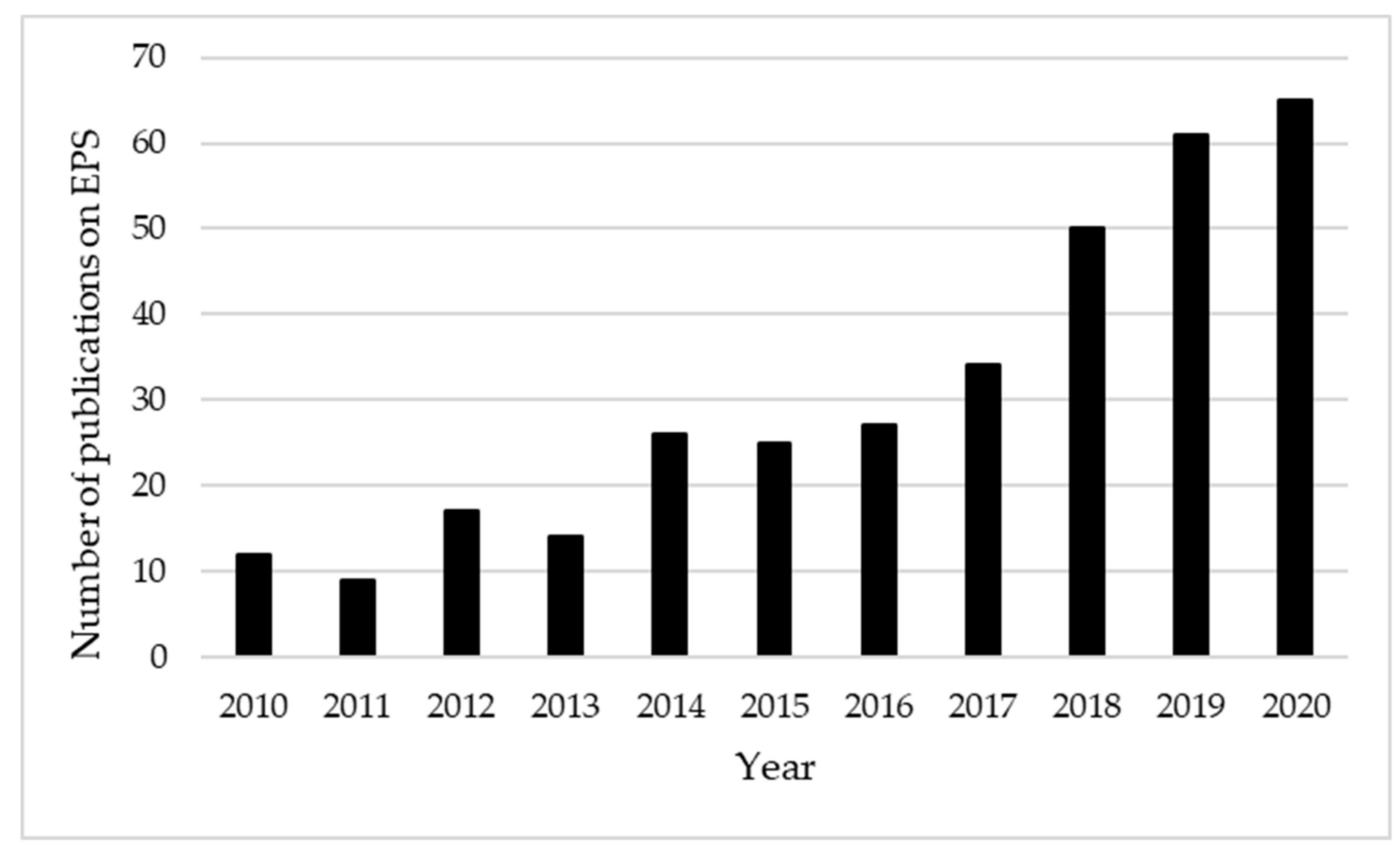

Figure A2. Number of publications on EPS per year, as analyzed in the literature review. 
Table A4. Sources of papers screened in the literature review on EPS and the percentage they represented out of the total sample $(\mathrm{n}=174)$. Sources linked to only one article are grouped under "Other".

\begin{tabular}{|c|c|}
\hline Source (Name of Journal) & $\%$ \\
\hline Energy and Buildings & 8.7 \\
\hline Construction and Building Materials & 6.4 \\
\hline Journal of Cleaner Production & 2.3 \\
\hline Materials & 2.3 \\
\hline Journal of Building Engineering & 2.0 \\
\hline Case Studies in Thermal Engineering & 1.7 \\
\hline Chemosphere & 1.7 \\
\hline Fire Technology & 1.7 \\
\hline Journal of Building Physics & 1.7 \\
\hline Applied Energy & 1.5 \\
\hline Building and Environment & 1.5 \\
\hline Buildings & 1.5 \\
\hline Composites Part B: Engineering & 1.5 \\
\hline Sustainability (Switzerland) & 1.5 \\
\hline Applied Thermal Engineering & 1.2 \\
\hline Energy Sources, Part A: Recovery, Utilization and Environmental Effects & 1.2 \\
\hline Engineering Structures & 1.2 \\
\hline Materials and Structures/Materiaux et Constructions & 1.2 \\
\hline Advances in Materials Science and Engineering & 0.9 \\
\hline BioResources & 0.9 \\
\hline Case Studies in Construction Materials & 0.9 \\
\hline Energies & 0.9 \\
\hline Environmental Science and Technology & 0.9 \\
\hline Fire and Materials & 0.9 \\
\hline Fire Safety Journal & 0.9 \\
\hline Journal of Thermal Analysis and Calorimetry & 0.9 \\
\hline Advances in Building Energy Research & 0.6 \\
\hline Akustika & 0.6 \\
\hline Applied Sciences (Switzerland) & 0.6 \\
\hline Asian Journal of Civil Engineering & 0.6 \\
\hline Building Services Engineering Research and Technology & 0.6 \\
\hline Cement and Concrete Composites & 0.6 \\
\hline Energy & 0.6 \\
\hline Energy Education Science and Technology Part A: Energy Science and Research & 0.6 \\
\hline Environmental Engineering and Management Journal & 0.6 \\
\hline Environmental Science and Pollution Research & 0.6 \\
\hline European Journal of Environmental and Civil Engineering & 0.6 \\
\hline International Journal of Engineering and Advanced Technology & 0.6 \\
\hline International Journal of Thermophysics & 0.6 \\
\hline Journal of Adhesion Science and Technology & 0.6 \\
\hline Journal of Advanced Research in Fluid Mechanics and Thermal Sciences & 0.6 \\
\hline Journal of Applied Fire Science & 0.6 \\
\hline Journal of Applied Polymer Science & 0.6 \\
\hline Journal of Cellular Plastics & 0.6 \\
\hline Journal of Environmental Engineering (Japan) & 0.6 \\
\hline Journal of Green Building & 0.6 \\
\hline Journal of Materials in Civil Engineering & 0.6 \\
\hline Journal of Materials Science & 0.6 \\
\hline Journal of Thermal Science and Technology & 0.6 \\
\hline Journal of Thermoplastic Composite Materials & 0.6 \\
\hline Kunststoffe International & 0.6 \\
\hline Metrologia & 0.6 \\
\hline Renewable and Sustainable Energy Reviews & 0.6 \\
\hline Science of the Total Environment & 0.6 \\
\hline Structural Concrete & 0.6 \\
\hline Tehnicki Vjesnik & 0.6 \\
\hline Thermal Science and Engineering Progress & 0.6 \\
\hline Other & 34.1 \\
\hline
\end{tabular}

\section{References}

1. Kirchherr, J.; Reike, D.; Hekkert, M. Conceptualizing the circular economy: An analysis of 114 definitions. Resour. Conserv. Recycl. 2017, 127, 221-232. [CrossRef]

2. Eurostat. Generation of Waste by Waste Category, Hazardousness and NACE Rev. 2 Activity; Eurostat: Luxembourg, 2016. 
3. EC Communication from the Commission to the European Parliament, the Council, the European Economic and Social Committee and the Committee of the Regions. A new Circular Economy Action Plan for a Cleaner and More Competitive Europe; European Comission: Brussels, Belgium, 2020.

4. Hodge, M.; Ochsendorf, J.; Fernández, J. Quantifying potential profit from material recycling: A case study in brick manufacturing. J. Clean. Prod. 2010, 18, 1190-1199. [CrossRef]

5. Sieffert, Y.; Huygen, J.; Daudon, D. Sustainable construction with repurposed materials in the context of a civil engineeringarchitecture collaboration. J. Clean. Prod. 2014, 67, 125-138. [CrossRef]

6. Orsini, F.; Marrone, P. Approaches for a low-carbon production of building materials: A review. J. Clean. Prod. 2019, 241, 118380. [CrossRef]

7. Fatta, D.; Papadopoulos, A.; Avramikos, E.; Sgourou, E.; Moustakas, K.; Kourmoussis, F.; Mentzis, A.; Loizidou, M. Generation and management of construction and demolition waste in Greece-an existing challenge. Resour. Conserv. Recycl. 2003, 40, 81-91. [CrossRef]

8. Duran, X.; Lenihan, H.; O’Regan, B. A model for assessing the economic viability of construction and demolition waste recyclingthe case of Ireland. Resour. Conserv. Recycl. 2006, 46, 302-320. [CrossRef]

9. Mhatre, P.; Panchal, R.; Singh, A.; Bibyan, S. A systematic literature review on the circular economy initiatives in the European Union. Sustain. Prod. Consum. 2021, 26, 187-202. [CrossRef]

10. Roberts, B.; Webber, M.; Ezekoye, O. Development of a multi-objective optimization tool for selecting thermal insulation materials in sustainable designs. Energy Build. 2015, 105, 358-367. [CrossRef]

11. IEA. Tracking Buildings; IEA: Paris, France, 2020.

12. Wahlström, M.; Bergmans, J.; Teittinen, T.; Bachér, J.; Smeets, A.; Paduart, A. Construction and Demolition Waste: Challenges and Opportunities in a Circular Economy; European Environment Agency: Copenhagen, Denmark, 2020.

13. Heller, N.; Flamme, S. Waste management of deconstructed external thermal insulation composite systems with expanded polystyrene in the future. Waste Manag. Res. 2020, 38, 400-407. [CrossRef]

14. Knutsen, H.; Arp, H.P.H. Preventing brominated flame retardants from occurring in recycled expanded polystyrene: Comparing Norwegian visual sorting with advanced screening methods. J. Hazard. Mater. Lett. 2021, 2, 100016. [CrossRef]

15. Schlummer, M.; Maurer, A.; Wagner, S.; Berrang, A.; Fell, T.; Knappich, F. Recycling of flame retarded waste polystyrene foams (EPS and XPS) to PS granules free of hexabromocyclododecane (HBCDD). Adv. Recycl. Waste Manag. 2017, 2, 5. [CrossRef]

16. Wiprächtiger, M.; Haupt, M.; Heeren, N.; Waser, E.; Hellweg, S. A framework for sustainable and circular system design: Development and application on thermal insulation materials. Resour. Conserv. Recycl. 2020, 154, 104631. [CrossRef]

17. Potting, J.; Hanemaaijer, A. Circular Economy: What We Want to Know and Can Measure. Framework and Baseline Assessment for Monitoring the Progress of the Circular Economy in the Netherlands; PBL Netherlands Environmental Assessment Agency: The Hague, The Nethelands, 2018; p. 92.

18. Sa, C.I. Energie- und Ressourcen-Management GmbH Entsorgungssituation von Dämmmaterialien in Der Schweiz. Im Auftrag Des Bundesamtes Für Umwelt (BAFU); CSD INGENIEURS SA: Carouge, Switzerland, 2016.

19. Bao, Z.; Lu, W. Developing efficient circularity for construction and demolition waste management in fast emerging economies: Lessons learned from Shenzhen, China. Sci. Total. Environ. 2020, 724, 138264. [CrossRef]

20. Giama, E.; Papadopoulos, A. Benchmarking carbon footprint and circularity in production processes: The case of stonewool and extruded polysterene. J. Clean. Prod. 2020, 257, 120559. [CrossRef]

21. EUMEPS. Available online: https:/ / eumeps.construction/product/ faq2020 (accessed on 12 October 2021).

22. Silva, K.D.C.; Silva, G.C.; Natalli, J.F.; Mendes, J.C.; Silva, G.J.B.; Peixoto, R.A.F. Rock wool waste as supplementary cementitious material for portland cement-based composites. ACI Mater. J. 2018, 115, 653-661. [CrossRef]

23. Linnenluecke, M.K.; Marrone, M.; Singh, A. Conducting systematic literature reviews and bibliometric analyses. Aust. J. Manag. 2020, 45, 175-194. [CrossRef]

24. Da Costa Fernandes, S.; Pigosso, D.C.; McAloone, T.C.; Rozenfeld, H. Towards product-service system oriented to circular economy: A systematic review of value proposition design approaches. J. Clean. Prod. 2020, 257, 120507. [CrossRef]

25. Tomino, A.C.; Perić, M.; Wise, N. Assessing and considering the wider impacts of sport-tourism events: A research agenda review of sustainability and strategic planning elements. Sustainability 2020, 12, 4473. [CrossRef]

26. De Oliveira, C.T.; Luna, M.M.; Campos, L.M. Understanding the Brazilian expanded polystyrene supply chain and its reverse logistics towards circular economy. J. Clean. Prod. 2019, 235, 562-573. [CrossRef]

27. Creswell, J.W.; Shope, R.; Clark, P.; Green, D.O. How interpretive qualitative research extends mixed methods research. Res. Sch. 2006, 13, 1-11.

28. Flick, U.; von Kardoff, E.; Steinke, I. A Companion to Qualitative Research; Sage: London, UK, 2004.

29. Ørngreen, R.; Levinsen, K. Workshops as a research methodology. Electron. J. E-Learn. 2017, 15, 70-81.

30. Ingrao, C.; Scrucca, F.; Tricase, C.; Asdrubali, F. A comparative life cycle assessment of external wall-compositions for cleaner construction solutions in buildings. J. Clean. Prod. 2016, 124, 283-298. [CrossRef]

31. Kaya, A.; Kar, F. Properties of concrete containing waste expanded polystyrene and natural resin. Constr. Build. Mater. 2016, 105, 572-578. [CrossRef]

32. Banciu, C.; Bara, A.; Chitanu, E.; Marinescu, V.; Sbarcea, G.; Ion, I. The effect of process parameters on the electrospun polystyrene fibers. Ind. Text. 2018, 69, 263-269. [CrossRef] 
33. Long, W.-J.; Lin, C.; Tan, X.-W.; Tao, J.-L.; Ye, T.-H.; Luo, Q.-L. Structural applications of thermal insulation alkali activated materials with reduced graphene oxide. Materials 2020, 13, 1052. [CrossRef]

34. Yliniemi, J.; Walkley, B.; Provis, J.; Kinnunen, P.; Illikainen, M. Nanostructural evolution of alkali-activated mineral wools. Cem. Concr. Compos. 2020, 106, 103472. [CrossRef]

35. Nguyen, H.; Kaas, A.; Kinnunen, P.; Carvelli, V.; Monticelli, C.; Yliniemi, J.; Illikainen, M. Fiber reinforced alkali-activated stone wool composites fabricated by hot-pressing technique. Mater. Des. 2020, 186, 108315. [CrossRef]

36. Drage, D.S.; Sharkey, M.; Abdallah, M.A.-E.; Berresheim, H.; Harrad, S. Brominated flame retardants in Irish waste polymers: Concentrations, legislative compliance, and treatment options. Sci. Total. Environ. 2018, 625, 1535-1543. [CrossRef]

37. Dunster, A.M. Industrial Sector Study on the Utilization of Alternative Materials in the Manufacture of Mineral Wool Insulation. 2007. Available online: http:/ / sciencesearch.defra.gov.uk/Document.aspx?Document=WR0115_8432_FRA.pdf (accessed on 12 October 2021).

38. Yuan, H.; Shen, L.; Hao, J.J.; Lu, W. A model for cost-benefit analysis of construction and demolition waste management throughout the waste chain. Resour. Conserv. Recycl. 2011, 55, 604-612. [CrossRef]

39. Meinander, M.; Mroueh, U.-M.; Bacher, J.; Laine-Ylijoki, J.; Wahlström, M.; Jermakka, J.; Teirasvuo, N.; Kuosa, H.; Törn, M.; Laaksonen, J.; et al. Directions of Future Developments in Waste Recycling; VTT Technical Research Centre of Finland: Espoo, Finland, 2012; p. 142.

40. Müller, A.; Leydolph, B.; Stanelle, K. Recycling mineral wool waste: Technologies for the conversion of the fiber structure, Part 1. Interceram 2009, 58, 378-381.

41. Väntsi, O.; Kärki, T. Mineral wool waste in Europe: A review of mineral wool waste quantity, quality, and current recycling methods. J. Mater. Cycles Waste Manag. 2013, 16, 62-72. [CrossRef]

42. Wrap. Recycling of Mineral Wool Composites Panels into New Raw Materials. 2008. Available online: https://www.yumpu. com/en/document/read/35321240/mineral-wool-composite-panels-wrap (accessed on 12 October 2021).

43. Hahladakis, J.N.; Purnell, P.; Iacovidou, E.; Velis, C.A.; Atseyinku, M. Post-consumer plastic packaging waste in England: Assessing the yield of multiple collection-recycling schemes. Waste Manag. 2018, 75, 149-159. [CrossRef]

44. Hansen, E.G.; Schmitt, J.C. Orchestrating cradle-to-cradle innovation across the value chain: Overcoming barriers through innovation communities, collaboration mechanisms, and intermediation. J. Ind. Ecol. 2021, 25, 627-647. [CrossRef]

45. Uusikartano, J.; Väyrynen, H.; Aarikka-Stenroos, L. Public agency in changing industrial circular economy ecosystems: Roles, modes and structures. Sustainability 2020, 12, 10015. [CrossRef]

46. Mahpour, A. Prioritizing barriers to adopt circular economy in construction and demolition waste management. Resour. Conserv. Recycl. 2018, 134, 216-227. [CrossRef]

47. Abildgaard, J.S.; Saksvik, P.Ø.; Nielsen, K. How to measure the intervention process? An assessment of qualitative and quantitative approaches to data collection in the process evaluation of organizational interventions. Front. Psychol. 2016, 7, 1380. [CrossRef] [PubMed]

48. MNP. Documentation of Key Findings of the Workshop on Barriers to Green Mining Innovation in Canada; MNP: Regina, SK, Canada, 2013.

49. Iodice, S.; Garbarino, E.; Cerreta, M.; Tonini, D. Sustainability assessment of construction and demolition waste management applied to an Italian case. Waste Manag. 2021, 128, 83-98. [CrossRef]

50. Joensuu, T.; Edelman, H.; Saari, A. Circular economy practices in the built environment. J. Clean. Prod. 2020, $276,124215$. [CrossRef]

51. Gálvez-Martos, J.-L.; Styles, D.; Schoenberger, H.; Zeschmar-Lahl, B. Construction and demolition waste best management practice in Europe. Resour. Conserv. Recycl. 2018, 136, 166-178. [CrossRef]

52. Guerra, B.C.; Leite, F. Circular economy in the construction industry: An overview of United States stakeholders' awareness, major challenges, and enablers. Resour. Conserv. Recycl. 2021, 170, 105617. [CrossRef]

53. Ghaffar, S.H.; Burman, M.; Braimah, N. Pathways to circular construction: An integrated management of construction and demolition waste for resource recovery. J. Clean. Prod. 2020, 244, 118710. [CrossRef]

54. Demacsek, C.; Tange, L.; Reichenecker, A.; Altnau, G. PolyStyreneLoop-The circular economy in action. In IOP Conference Series: Earth and Environmental Science; IOP Publishing: Bristol, UK, 2019; Volume 323, p. 012149.

55. Doğan-Sağlamtimur, N.; Bilgil, A.; Öztürk, B. Reusability of ashes for the building sector to strengthen the sustainability of waste management. In Handbook of Research on Emerging Technologies for Effective Project Management; IGI Global: Hershey, PA, USA, 2018; pp. 265-281.

56. Migliore, M. Circular economy and upcycling of waste and pre-consumer scraps in construction sector. The role of information to facilitate the exchange of resources through a virtual marketplace. Environ. Eng. Manag. J. 2019, 18, $297-2303$.

57. Ahmed, R.R.; Zhang, X. Multi-stage network-based two-type cost minimization for the reverse logistics management of inert construction waste. Waste Manag. 2021, 120, 805-819. [CrossRef]

58. Wijewickrama, M.; Chileshe, N.; Rameezdeen, R.; Ochoa, J.J. Quality assurance in reverse logistics supply chain of demolition waste: A systematic literature review. Waste Manag. Res. 2021, 39, 3-24. [CrossRef] [PubMed]

59. Pushpamali, N.; Agdas, D.; Rose, T.M. Strategic decision making in construction supply chains: A comparison of reverse logistics strategies. Front. Built Environ. 2020, 6, 593372. [CrossRef] 
60. Trochu, J.; Chaabane, A.; Ouhimmou, M. A two-stage stochastic optimization model for reverse logistics network design under dynamic suppliers' locations. Waste Manag. 2019, 95, 569-583. [CrossRef]

61. Heisel, F.; Rau-Oberhuber, S. Calculation and evaluation of circularity indicators for the built environment using the case studies of UMAR and Madaster. J. Clean. Prod. 2020, 243, 118482. [CrossRef]

62. Munaro, M.R.; Tavares, S.F. Materials passport's review: Challenges and opportunities toward a circular economy building sector. Built Environ. Proj. Asset Manag. 2021. [CrossRef]

63. Honic, M.; Kovacic, I.; Rechberger, H. Improving the recycling potential of buildings through material passports (MP): An Austrian case study. J. Clean. Prod. 2019, 217, 787-797. [CrossRef]

64. Hickle, G.T. An examination of governance within extended producer responsibility policy regimes in North America. Resour. Conserv. Recycl. 2014, 92, 55-65. [CrossRef]

65. Durão, V.; Silvestre, J.D.; Mateus, R.; de Brito, J. Assessment and communication of the environmental performance of construction products in Europe: Comparison between PEF and EN 15804 compliant EPD schemes. Resour. Conserv. Recycl. 2020, $156,104703$. [CrossRef]

66. Tam, V.W.; Shen, L.; Fung, I.W.; Wang, J. Controlling construction waste by implementing governmental ordinances in Hong Kong. Constr. Innov. 2007, 7, 149-166. [CrossRef]

67. Benachio, G.L.F.; Freitas, M.D.C.D.; Tavares, S.F. Circular economy in the construction industry: A systematic literature review. J Clean. Prod. 2020, 260, 121046. [CrossRef]

68. Hossain, U.; Ng, S.T.; Antwi-Afari, P.; Amor, B. Circular economy and the construction industry: Existing trends, challenges and prospective framework for sustainable construction. Renew. Sustain. Energy Rev. 2020, 130, 109948. [CrossRef]

69. Granstranda, O.; Holgerssonb, M. Innovation ecosystems: A conceptual review and a new definition. Technovation 2020, 90, 102098. [CrossRef]

70. Konietzko, J.; Bocken, N.; Hultink, E.J. Circular ecosystem innovation: An initial set of principles. J. Clean. Prod. 2020, $253,119942$. [CrossRef] 